\title{
Identify the correlation between the teaching perspectives and student evaluation: A case study of a sample university in Ho Chi Minh city
}

\author{
Huy Nguyen ${ }^{1, *}$ and Radim Briš ${ }^{2}$ \\ ${ }^{1}$ Faculty of Mathematics and Statistics, Ton Duc Thang University, Ho Chi Minh City, Vietnam \\ ${ }^{2}$ Department of Applied Mathematics, Faculty of Electrical Engineering and Computer Science, VŠB \\ -Technical University of Ostrava, Ostrava, Czech Republic
}

\begin{abstract}
Education is a critical issue in any cultural background. In fact, the quality of teaching shall be considered and linked with student evaluation because there seems to have a strong correlation between them. This study aims to understand the different perspectives on teaching by academic staffs of a university $\mathrm{X}$ in Ho Chi Minh City and also is to determine whether there are one or two dominant teaching perspective preferences. In addition, the students' comments were also collected and investigated to identify whether or not there are relationships between these dominant teaching perspectives and student end-of-course evaluations. Finally, the researcher proposed a new form of evaluation to help measure better students' expectations.
\end{abstract}

\section{Introduction}

Teaching adults and higher education is a major issue which had been discussed by Kember since 1997 and no further published researches were made beyond that one. Understanding of the teaching perspective is not only to specify what the teachers should and are supposed to do in order to successfully fulfill students' expectations but also to improve the quality of teaching with respect to student evaluations. Even though every educator has different preferred styles of teaching, then they have to be followed by set of standards.

Moreover, in different countries the teaching strategies may vary a little or much depending on their students' needs and expectations. For example, education in Australia tend to be more relaxed than in Vietnam as the Australian teachers allow their students to learn individually, meanwhile Vietnamese students are required to study with disciplines and they are more likely told what to do and learn rather than self-study. Hence, students may not fully understand the reasons for studying some courses and how to apply in the future career and this causes less motivation in their courses.

\footnotetext{
* Corresponding author: nguyenbachuy@,tdtu.edu.vn
} 


\section{Literature review}

Kember identified five significant teaching perspectives, such as: transmission, apprenticeship, developmental, nurturing and social reform.

Transmission: A good teacher should know how to link his/her teaching to the content as a solid tool in order to effectively transmit message or knowledge to learners.

Apprenticeship: Teachers play an important role in helping their students to conceive the materials with ease and comfort. Different levels of students from not good to excellent need different levels of guidance so teachers have to have lots of experience to satisfy their needs.

Developmental: Content must be appropriately prepared and conducted. Shall teachers choose an easy way to approach their learners to engage in the materials from simplex to complex, also combining asking questions and examples to illustrate their points more comprehensible.

Nurturing: Teaching should come from heart and head. People are more motivated to work without fear or menace. Learners are really educated if they know the outcomes of what they are doing and trying hard for, also their achievement is a combination of their ability and effort.

Social reform: Shall good teachers make their students aware of the values of knowledge and how and when to apply in real life. Each graduate will contribute to society different knowledge which has been taught from classes and from valuable experiences earning from field trip or internship. Each person has different preferred style of learning, however those diverse styles are identified in the classroom as every student is taught in the same way as others (Goodlad, 1984). Students with clear identification of learning style usually achieve better results than those do not. For example: practionners concluded that grade-point averages for those who have clearly identified their preferred learning style much higher than others (Andrews, 1990; Lemmon, 1985; Stone, 1992; Turner, 1993). The best way to teach learners no matter how old they are is firstly to help them deeply understand conceptual backgrounds then more details should be given along with lots of examples so they could systemize the materials themselves at home. In that case they do not fear or worry about what they have just been taught.

'Quality Teaching' and 'Successful Teaching' are distinguished by Fenstermacher and Richardson in 2005 as follows:

A quality teaching is more than just transmitting the knowledge to the learners, but also the way the instructors teach. Fenstermacher and Richardson refer it as by good teaching we mean that the content taught accords with disciplinary standards of adequacy and completeness, and that the methods employed are age appropriate, morally defensible, and undertaken with the intention of enhancing the learner's competence with respect to the content studied (p.191). Meanwhile, 'successful teaching' is evaluated based on student outcomes through assessment and according to these authors it is referred as follows: by successful teaching we mean that the learner actually acquires, to some reasonable and acceptable level of proficiency, what the teacher is engaged in teaching (p.191).

\section{Research Methodology}

This is a quantitative study; we have conducted survey approach in order to collect students' perceptions and comments. The sets of questions consist of two types: yes/no and open-ended. The students from different schools and departments were selected to answer the survey, 150 surveys were given out and only 140 were found as complete data that can be used for analysis. Surveys comprised 15 questions (12 multiple choices and 3 openedended) and all respondents belong to $19-24$ group. The majority was female's $65 \%$ and 
$35 \%$ males; the participants come from various schools and departments such as: $22.14 \%$ belonged to Business Administration (BA), 7.14\% to Computer Science Engineering (CSE), $7.14 \%$ to Electrical Engineering (EE), $11.43 \%$ to Biotechnology (BT), $7.86 \%$ to Mathematics (MA), 7.86\% to Physics (PH), 8.57\% to English (EN), 8.57\% to Industrial \& Systems Engineering (ISE), $12.86 \%$ to Biomedical Engineering (BME) and $6.43 \%$ to Chemistry $(\mathrm{CH})$ - a small Department which belongs to School of Biotechnology.

\section{Data Analysis}

We were considering 2016 - 2017 academic year for both semesters one and two (summer semester excluded).

The following tables show the comparison of overall mean scores between two semesters.

Table 1. Mean scores between Semester $1 \& 2$.

\begin{tabular}{|c|c|c|c|c|}
\hline Order & School/Dept & Sem 1 & Sem 2 & Comment \\
\hline 1 & Chemistry & 4.5 & 4.13 & Not improved \\
\hline 2 & Physics & 4.14 & 4.05 & Not improved \\
\hline 3 & English & 4.12 & 4.04 & Not improved \\
\hline 4 & Computer Science Engineering & 4.10 & 4.12 & Improved \\
\hline 5 & Biomedical Engineering & 4.09 & 4.43 & Dramatically Improved \\
\hline 6 & Biotechnology & 4.08 & 4.03 & Not improved \\
\hline 7 & Industrial \& Systems Engineering & 4.03 & 4.0 & Not improved \\
\hline 8 & Electrical Engineering & 4.02 & 4.0 & Not improved \\
\hline 9 & Business Administration & 3.99 & 3.94 & Not improved \\
\hline 10 & Mathematics & 3.71 & 3.78 & Improved \\
\hline 11 & University X & $\mathbf{4 . 0 4}$ & $\mathbf{3 . 9 9}$ & Not improved \\
\hline
\end{tabular}

The second semester's average scores varied less than first semester did with a standard deviation of 0.158 compared to 0.183 for Semester 1. Considering compulsory subjects such as Mathematics, Physics, Chemistry and English, only Mathematics was evaluated with the least score due to its complexity and compulsoriness. Some students from other Schools or Departments which are non-mathematics oriented most likely dislike this subject as they could not see its practicality and realness to their future career. As discussed in literature review, one of the teaching responsibilities was that the lecturers shall explain to their students how to link the theory and the practice during the courses and also convince them how to apply it in specific cases.

The quality of teachers was also evaluated and the following table will show an overall picture for the academic year 2016-2017 : 
Table 2. Mean scores for quality of teachers between Semester $1 \& 2$.

\begin{tabular}{|c|c|c|c|c|}
\hline \multicolumn{2}{|c|}{ Semester 1 } & & \multicolumn{2}{|c|}{ Semester 2 } \\
\hline $\mathrm{X}$ & Score & School/Dept & Score & $\mathrm{X}$ \\
\hline \multirow{5}{*}{$\mathbf{4 . 0 3}$} & 3.97 & BA & 3.93 & \\
\cline { 2 - 4 } & 4.07 & $\mathrm{BT}$ & 4.03 & \\
\cline { 2 - 4 } & 4.06 & $\mathrm{BME}$ & 4.42 & \\
\cline { 2 - 4 } & 4.42 & $\mathrm{CH}$ & 4.11 & \multirow{3}{*}{$\mathbf{3 . 9 8}$} \\
\cline { 2 - 4 } & 4.03 & $\mathrm{EE}$ & 3.98 & \\
\cline { 2 - 4 } & 4.09 & $\mathrm{EN}$ & 4.01 & \\
\cline { 2 - 4 } & 4.00 & $\mathrm{ISE}$ & 3.99 & \\
\cline { 2 - 4 } & 4.12 & $\mathrm{CSE}$ & 4.13 & \\
\cline { 2 - 4 } & 3.67 & $\mathrm{MA}$ & 3.77 & \\
\cline { 2 - 4 } & 4.17 & $\mathrm{PH}$ & 4.06 & \\
\hline
\end{tabular}

In overall, the range of the mean scores is narrower in semester 2 which was [3.77, 4.42] compared to semester 1 was [3.67, 4.42], also almost Schools and Departments' scores tend to slightly decrease. Moreover, only a few average scores' improved such as of BME, CSE and MA's, and BME had remarkable changes. This worries the university a little as the quality of teaching in general and the quality of teachers in particular seems to become worse.

Teaching is a crucial tool in education as it transmits knowledge from one to others, thus the instructor must be knowledgeable and have strong teaching skills to help their students to gain the best understanding in no matter what subjects are.

Taking consideration on the fact that the instructor shall link the practice and the theory during teaching is also an important manner. Almost Schools and Departments did well with the average score above 80 per cent, yet only Mathematics Department achieved the lowest mark which is odd as this is a natural basic subject which is applied in many areas in real life and not all students were not told how to use the theory to solve the real life problem. Therefore, this Department only got 3.75 out of 5.0. This score is indeed very low as all students of this university had to study Mathematics in their degrees. This mark reflects on a whole population of X's students. In contrast, in second semester there were two more School and Department together with Mathematics Department achieved the lower average score than 80 per cent. In fact, it shows that the lecturers of those schools may have not clarified the necessity and applicability of the subjects they were delivering. The students need to be fully motivated by understanding the reasons why they should learn the subjects, especially basic subjects such as Mathematics, Physics and Chemistry.

Next, communicating in class is also an important factor in learning as the instructors can see whether their students are up to the level that they expected or not and if any gaps exist then they could fill in. Questions and answers are correlated with the aim of linking the lectures to the students' understandings and also to make the class's atmosphere more exciting, another words it is called 'interaction'. This has been discussed in the literature review. According to the results, only 4 out of 10 Schools/Departments achieved the average score for this factor which was higher than the X's mean score in the first semester and oppositely there was 6 out of 10 Schools/Departments got the higher mean score than the overall one in second semester. Encouraging students to communicate verbally is also a strategy in teaching because sometimes students may have clever questions which might make their lecturers think carefully before answering. Another issue is that the students are most likely shy to ask questions during lectures because they worry that their questions 
might be too simple. And the consequence for this issue is that they will fall behind the class time after time. As a result, the instructors are necessary to encourage their students to speak and interact as much as possible during the class.

In education, assessment is also needed. As it will reflect and evaluate what students have learnt and expect their applicable skills. Not only assess the theories but also test how they can deal with real world problem-solving. The overall mean score of a whole university for this question was under 80 per cent and most of Schools and Departments got higher scores than the overall mean score, except BA. In fact, there were in total of three Schools/Departments with the scores below the overall average and once again BA achieved the least score of nearly 75 per cent compared to 78 per cent in overall. Core subjects as Chemistry and Mathematics both got the average score higher than the overall one in both semesters. This fulfilled the students' needs. Setting assignments, projects or even homeworks are totally up to the instructors so they have full right to design and set their students in a few or many assessment pieces also depending on the subjects. The more assessment pieces involves the more work the lectures will do in checking, marking and providing feedback for them. Students will learn from their mistakes given that full comments and suggestions shall be given by their teachers. Moreover, students need to be marked equally and fairly with clear marking schemes given and no discrimination shall exist in any case. In overall, in both semester every School and Department got quite good score, however only Mathematics Department obtained a little lower average score than others for both semester.

Outside class assistance can be of importance to students for some reasons. First of all is to help the students to clarify misunderstanding or unsure problems occurred in class that the students did not dare to ask. Second is to guide them in doing projects or even some difficult homework. Third is to talk to the students and sometimes motivate them. Relying on the set class times is not always possible to answers all questions raised. The overall score for this matter was 3.96 in semester one and downed to 3.89 in semester two, in addition almost Schools and Departments achieved lower scores in second semester, except BME and CSE which have been improved a little. In general, in education there should have much volunteer support offered by the teachers to help learners to gain deep understanding together with sharing valuable experiences throughout teaching times.

The last issue needs to be taken consideration is the helpfulness of the courses. In fact, students will not be aware of its usefulness without clarifying and connecting what they were studying with the practice. In both semesters, MA and PH had the mean scores below the X's mean score which might be not acceptable as these subjects are basic nature courses that will be surely somehow applied in real life. For some courses such as BA's, BT's, EE's, etc, students may not fully understand how to apply the knowledge as the materials may be quite challenging and difficult to understand. Also, some subjects are pre-requisites for others so the students have to complete all of them according to the set curriculum. Hence, if they can be clarified with the reasons why they were taking the courses and how to apply the knowledge to the future careers then they will surely be motivated to learn the courses more effectively. All these tasks are definitely teachers' responsibilities.

Based on the above results, we may not be able to judge the quality of teaching as well as of lecturers and instructors. However, we use these facts to revise for a new version of "Course Evaluation Form" with some changes in order to suit students' needs and expectations. Please refer to Appendix.

First of all, the name of the form is recommended change from "Course Evaluation Form" to "Teaching Evaluation Form" as we should not combine "teaching" \& "course" 
evaluations in the same form as before. The courses' contents are periodically reviewed each year and are done by the Academic Board so the students may not have enough experience to suggest how to change.

Secondly, most of questions have been revised, rephrased and re-ordered in a different way. These questions have been considered and suggested based on the discussed teaching perspectives in the literature review such as: transmission, apprenticeship, developmental, nurturing and social reform with the objective of defining the correlation between teaching perspectives and student evaluation. The students may not evaluate correctly without appropriate questions. These new questions mainly focus on teaching style and the interaction between lecturers and students as we are aware of the fact that it is not necessarily right to say a high level educated lecturer will be a good lecturer, it depends on how he or she interacts with students and also how to transmit their knowledge in the best way. Teaching is not an easy task as the lecturers have to be patient to deal with different level of students in the same class. Lecturers shall practice their skills every time they come to class as to improve their teaching skills better. In addition, they should achieve the scores that they have been evaluated by their students in order to revise what they have done good and what not too good. Sometimes they might get some comments and they should not ignore those.

However, there is a fact that we have to be aware of when doing this research is the use of feedback as it is sometimes dangerous to rely on and the reason for that is sometimes a strict lecturer will be badly evaluated which does not mean that that lecturer is not good and vice versus. But if the result badly repeated over and over again so it may prove the quality of that lecturer to be true.

Revising for a better version of the teaching evaluation form is important as the students' expectations vary from time to time. Feedback is just used as a tool to identify the gap between "teaching" and students not for evaluating the quality of teachers. In fact the outcome for this research is a revised teaching evaluation form to see whether it will be effective or not.

The results show that over 90 per cent of participants agreed that their lectures should have a mastery of the subjects they teach as well as being not too easy nor too strict in teaching as it may cause panic in learning. Also, more than 85 per cent people wanted to be clearly defined the objectives of any subjects they study at the beginning and how to apply in real life. About a third commented that their workload is currently quite heavy and they suggested that the weithing of assessments shall be reduced and the group assignments should be worth more because in that case the students will have more time to maximize their research's abilities as well as team work skills in order to produce the good projects. They mentionned "We do and we can learn from it, we can not learn from what we are assessed". Therefore, the lecturers may take this consideration to adjust the syllabi to suit their students' needs.

In addition, 100 per cent of participants agreed that the strictness of lecturers merely affected their learning. As a result, this issue should be carefully considered to improve the learning environment in the university. A super easy-going lecturer not necessarily means that he or she will teach well, the advantage for this person is easier to get closer to students so he or she may be able to assist the students better.

Interaction between the lecturers and the students are unfortunately not highly evaluated as students said that during lectures not many lecturers offered them a chance to speak so they did not dare to ask when needed. Interacting in class not only to clarify the 


\section{ICM 2018}

confusion but also share knowledge in many dimensions. Moreover, about half of participants had the same feeling that in class they will only be told what to do and not to do in a single way not in multiple situations.

112 out of 140 students were satisfied with the assistance offered by their lecturers besides the official class times and tutorial classes. They found those extra helps very beneficial and valuable. There will be no better way to learn effectively if they do not fully understand the concepts or definitions. In education, "interaction" between the instructor and the learner is always crucial.

Table 3. Reliability Analysis

\begin{tabular}{|c|c|}
\hline Variables & Cronbach's Alpha \\
\hline Satisfaction (SA) & 0.742 \\
\hline Mastery of subject (MA) & 0.649 \\
\hline Strictness of lecturers (ST) & 0.823 \\
\hline Interaction (IN) & 0.775 \\
\hline Outside class assistance (OC) & 0.861 \\
\hline
\end{tabular}

According to standards, the reliability coefficient of 0.60 or higher is considered "reasonable acceptable" and in this study statistics shows above four variables are independent.

Pearson correlation allows us to determine the relationship between variables as it checks the "interdependency" of the variables considered in the model.

Table 4. Correlations

\section{Correlation: Satisfaction, Mastery of subject, Strictness, Interaction, Outside class assistance Correlations}

\begin{tabular}{lrrrr} 
& Satisfaction & Mastery of subje & Strictness & Interaction \\
\hline Mastery of subje & -0.114 & & & \\
& 0.180 & & & \\
Strictness & 0.029 & 0.064 & & \\
& 0.738 & 0.453 & & \\
Interaction & -0.052 & 0.001 & 0.238 & \\
& 0.541 & 0.993 & 0.005 & \\
Outside class as & -0.186 & -0.015 & -0.033 & 0.041 \\
& 0.028 & 0.864 & 0.701 & 0.633 \\
$\begin{array}{l}\text { Cell Contents } \\
\text { Pearson correlation } \\
\quad \text { P-Value }\end{array}$ & & & & \\
\end{tabular}


The correlations table indicated that there exists a positive association between satisfaction and outside class assistance $(\mathrm{r}=-0.186, \mathrm{n}=140, \mathrm{p}=0.028)$ and there exists no statistically significant linkage between satisfaction and mastery of subject $(\mathrm{r}=-0.114, \mathrm{n}=$ $140, \mathrm{p}=0.180)$, strictness $(\mathrm{r}=0.029, \mathrm{n}=140, \mathrm{p}=0.738)$ and interaction $(\mathrm{r}=-0.052, \mathrm{n}=$ $140, \mathrm{p}=0.541$ ). Outside class assistance is statistically significantly associated with none of the independent variables. Interaction is statistically significantly associated with strictness $(\mathrm{r}=0.238, \mathrm{n}=140, \mathrm{p}=0.005)$.

Table 5. Model summary

\begin{tabular}{|c|c|c|}
\hline Model & R Square & Adjusted R Square \\
\hline 1 & $0.0519^{\mathrm{a}}$ & 0.0238 \\
\hline 2 & $0.0502^{\mathrm{b}}$ & 0.0292 \\
\hline 3 & $0.0482^{\mathrm{c}}$ & 0.0343 \\
\hline 4 & $0.0346^{\mathrm{d}}$ & 0.0276 \\
\hline a. & Predictors: (Constant), MA, ST, IN, OC \\
\hline b. & Predictors: (Constant), MA, IN, OC \\
\hline c. & Predictors: (Constant), MA, OC \\
\hline d. & Predictors: (Constant), OC \\
\hline e. & Predictors: (Constant), OC \\
\hline
\end{tabular}

Model summary table shows suitability of the regression model to the specified data. Backward regression indicated fourth model to be the most significant one with $\mathrm{R}$ square value is 0.0346 this means outside class assistance can bring variation in satisfaction up to 3.46 per cent.

Table 6. Anova statistics

\begin{tabular}{|c|c|c|c|c|c|c|}
\hline \multicolumn{2}{|r|}{ Model } & $\begin{array}{l}\text { Adjusted Sum of } \\
\text { Squares }\end{array}$ & $\begin{array}{l}\text { Degree of } \\
\text { fredom }\end{array}$ & $\begin{array}{c}\text { Adjusted Mean } \\
\text { Square }\end{array}$ & $\mathbf{F}$ & p-value \\
\hline \multirow{3}{*}{1} & Regression & 4.9231 & 4 & 1.2308 & 1.85 & $0.123^{\mathrm{a}}$ \\
\hline & Residual & 89.8983 & 135 & 0.6659 & & \\
\hline & Total & 94.8214 & 139 & & & \\
\hline \multirow{3}{*}{2} & Regression & 4.7574 & 3 & 1.5858 & 2.39 & $0.071^{\mathrm{b}}$ \\
\hline & Residual & 90.0640 & 136 & 0.6622 & & \\
\hline & Total & 94.8214 & 139 & & & \\
\hline \multirow{3}{*}{3} & Regression & 4.570 & 2 & 2.2852 & 3.47 & $0.034^{\mathrm{c}}$ \\
\hline & Residual & 90.251 & 137 & 0.6588 & & \\
\hline & Total & 94.821 & 139 & & & \\
\hline \multirow{3}{*}{4} & Regression & 3.2790 & 1 & 3.2790 & 4.94 & $0.028^{\mathrm{d}}$ \\
\hline & Residual & 91.5425 & 138 & 0.66335 & & \\
\hline & Total & 94.8214 & 139 & & & \\
\hline & \multicolumn{6}{|c|}{ Predictors: (Constant), MA, ST, IN, OC } \\
\hline & \multicolumn{6}{|c|}{ Predictors: (Constant), MA, IN, OC } \\
\hline & \multicolumn{6}{|c|}{ Predictors: (Constant), MA, OC } \\
\hline & \multicolumn{6}{|c|}{ Predictors: (Constant), OC } \\
\hline & \multicolumn{6}{|c|}{ e. Dependent variable: SA } \\
\hline
\end{tabular}

Focusing on the fourth model, it can be found that outside class assistance can have a strong impact on the satisfaction $\mathrm{F}(1,138)=4.94, \mathrm{p}<0.05$. 
Table 7. Coefficients statistics

\begin{tabular}{|c|c|c|c|c|c|}
\hline \multicolumn{2}{|c|}{ Model } & Coefficient & SE Coef & T-value & p-value \\
\hline \multirow{4}{*}{1} & (Constant) & 5.040 & 0.502 & 10.05 & 0.000 \\
\cline { 2 - 6 } & MA & -0.1053 & 0.0741 & -1.42 & 0.158 \\
\cline { 2 - 6 } & ST & 0.0351 & 0.0704 & 0.50 & 0.619 \\
\cline { 2 - 6 } & IN & -0.0446 & 0.0703 & -0.63 & 0.527 \\
\hline \multirow{4}{*}{2} & OC & -0.1487 & 0.0678 & -2.19 & 0.030 \\
\cline { 2 - 6 } & (Constant) & 5.135 & 0.463 & 11.10 & 0.000 \\
\cline { 2 - 6 } & MA & -0.1029 & 0.0737 & -1.40 & 0.165 \\
\cline { 2 - 6 } & IN & -0.0362 & 0.0681 & -0.53 & 0.596 \\
\hline \multirow{3}{*}{3} & OC & -0.1502 & 0.0676 & -2.22 & 0.028 \\
\cline { 2 - 6 } & (Constant) & 5.003 & 0.389 & 12.86 & 0.000 \\
\hline \multirow{3}{*}{4} & MA & -0.1030 & 0.0735 & -1.40 & 0.164 \\
\cline { 2 - 6 } & OC & -0.1516 & 0.0674 & -2.25 & 0.026 \\
\cline { 2 - 6 } & (Constant) & 4.601 & 0.264 & 17.46 & 0.000 \\
\hline
\end{tabular}

Considering conclusions of hypotheses made for this study as follows:

\section{Hypothesis 1:}

Independent variables were employed as mastery of subject, strictness, interaction and outside class assistance and satisfaction as an dependent variable. It turned out three variables in the model that are having insignificant values such as mastery of subject $(\mathrm{t}=$ $1.42, \mathrm{p}=0.158)$, interaction $(\mathrm{t}=-0.63, \mathrm{p}=0.527)$, and the most insignificant variable that is strictness $(\mathrm{t}=0.50, \mathrm{p}=0.619)$ will be removed to improve the model. This concluded that there is no linkage between strictness and satisfaction.

\section{Hypothesis 2:}

In the second model, we still included three variables but two are again found to be not significant as mastery of subject $(\mathrm{t}=-1.40, \mathrm{p}=0.165)$ and the most insignificant variable interaction $(\mathrm{t}=-0.53, \mathrm{p}=0.596)$ will be excluded. This concluded that there is no linkage between interaction and satisfaction.

\section{Hypothesis 3:}

Although two variables have been eliminated, the model still needs to be reconsidered as another independent variable which is mastery of subject is found to be insignificant $(\mathrm{t}=$ $1.40, \mathrm{p}=0.164)$. This would make us accept our third hypothesis that is; there is no linkage between mastery of subject and satisfaction.

\section{Hypothesis 4:}

The last model only has outside class assistance exists to be found as the most significant one $(\mathrm{t}=-2.22, \mathrm{p}=0.028)$. It indicates that there is a statistical relationship between outside class assistance and satisfaction.

Hence, regression equation is as follows:

Satisfaction $=4.601+0.1503 *$ Outside class assistance 


\section{Conclusion}

Teaching that is not only a single task, but also a long process. A good teacher shall have a mastery of knowledge and know how motivate his/her students in learning process by giving clear explanations and linking theories to practice appropriately. More importantly, the teachers should define clearly the learning outcomes for their students at the beginning so they can see its importance and it will motivate them to complete the courses more efficiently. However, students' expectations may vary year after year, hence a revision of teaching evaluation form should be needed to match with the students' needs and expectations in learning. The outcome of this research is just simply a suggestion of a newer version of teaching evaluation form.

\section{References}

1. Dunn, R. \& Griggs, S.A. Multiculturalism and Learning Style. Wesport, Connectticut, London (1998).

2. Ingvarson, L., \& Rowe, K. Conceptualising and Evaluating Teacher Quality:

Substantive and Methodological Issues. The Australian Journal of Education, Vol. 52,

No.1, Apr 2008: 5-35. Available at:

http://search.informit.com.au/documentSummary; $\mathrm{dn}=058594415630070 ;$ res=IELHSS ISSN: 0004-9441 (2007).

3. Mitchell, K.J., Robinson, D.Z., Plake, B.S., \& Knowles, K.T. Testing Teacher

Candidates - The role of licensure tests in improving teacher quality. National Academy Press, Washington, DC: National Research Council (2001).

4. Qualters, D. What's your perspective on teaching. Issue No.4. St Thomas University (2002). 